\title{
Assessing the Activity of Multidrug Resistance-Associated Protein 1 at the Lung Epithelial Barrier
}

\author{
Severin Mairinger ${ }^{1}$, Johannes A. Sake ${ }^{2}$, Irene Hernández Lozano ${ }^{3}$, Thomas Filip ${ }^{1}$, Michael Sauberer ${ }^{1}$, Johann Stanek ${ }^{1}$, \\ Thomas Wanek ${ }^{1}$, Carsten Ehrhardt ${ }^{2}$, and Oliver Langer ${ }^{1,3,4}$

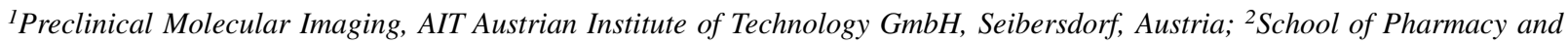 \\ Pharmaceutical Sciences and Trinity Biomedical Sciences Institute, Trinity College Dublin, Dublin, Ireland; ${ }^{3}$ Department of \\ Clinical Pharmacology, Medical University of Vienna, Vienna, Austria; and ${ }^{4}$ Division of Nuclear Medicine, Department \\ of Biomedical Imaging und Image-Guided Therapy, Medical University of Vienna, Vienna, Austria
}

\begin{abstract}
Multidrug resistance-associated protein 1 (adenosine triphosphatebinding cassette subfamily $\mathrm{C}$ member 1 [ABCC1]) is abundantly expressed at the lung epithelial barrier, where it may influence the pulmonary disposition of inhaled drugs and contribute to variability in therapeutic response. The aim of this study was to assess the impact of $\mathrm{ABCC} 1$ on the pulmonary disposition of 6 -bromo-7- ${ }^{11} \mathrm{C}$ methylpurine $\left({ }^{11} \mathrm{C}-\mathrm{BMP}\right)$, a prodrug radiotracer that is intracellularly conjugated with glutathione to form the ABCC1 substrate S-(6$\left(7-{ }^{11} \mathrm{C}\right.$-methylpurinyl))glutathione $\left({ }^{11} \mathrm{C}-\mathrm{MPG}\right)$. Methods: Groups of $A b c c 1^{(-)}$rats, wild-type rats pretreated with the $A B C C 1$ inhibitor MK571, and wild-type control rats underwent dynamic PET scans after administration of ${ }^{11} \mathrm{C}$-BMP intravenously or by intratracheal aerosolization. In vitro transport experiments were performed with unlabeled BMP on the human distal lung epithelial cell line $\mathrm{NCl}-$ H441. Results: The pulmonary kinetics of radioactivity significantly differed between wild-type and $A b c c 1^{(-)}$rats, but differences were more pronounced after intratracheal than after intravenous administration. After intravenous administration, lung exposure (area under the lung time-activity curve from 0 to 80 min after radiotracer administration $\left[\mathrm{AUC}_{\text {lung }}\right.$ ]) was $77 \%$ higher and the elimination slope of radioactivity washout from the lungs $\left(k_{E, \text { lung }}\right)$ was $70 \%$ lower in $A b c c 1^{(-/-)}$rats, whereas after intratracheal administration, $\mathrm{AUC}_{\text {lung }}$ was $352 \%$ higher and $k_{\mathrm{E}, \text { lung }}$ was $86 \%$ lower in $\mathrm{Abcc1^{(-/-) }}$ rats. Pretreatment with MK571 decreased $k_{\mathrm{E} \text {,lung }}$ by $20 \%$ after intratracheal radiotracer administration. Intracellular accumulation of MPG in NCl-H441 cells was significantly higher and extracellular efflux was lower in the presence than in the absence of MK571. Conclusion: PET with pulmonary administered ${ }^{11} \mathrm{C}-\mathrm{BMP}$ can measure $A B C C 1$ activity at the lung epithelial barrier and may be applicable in humans to assess the effects of disease, genetic polymorphisms, or concomitant drug intake on pulmonary ABCC1 activity.
\end{abstract}

Key Words: 6-bromo-7-11 C-methylpurine; lung epithelial barrier; multidrug resistance-associated protein 1; PET; pulmonary drug disposition

J Nucl Med 2020; 61:1650-1657

DOI: 10.2967/jnumed.120.244038

Received Feb. 24, 2020; revision accepted Mar. 19, 2020.

For correspondence or reprints contact: Oliver Langer, Preclinical Molecular Imaging, AIT Austrian Institute of Technology GmbH, 2444 Seibersdorf, Austria. E-mail: oliver.langer@ait.ac.at

Published online Apr. 13, 2020.

COPYRIGHT @ 2020 by the Society of Nuclear Medicine and Molecular Imaging.
$\mathcal{C}$ hronic respiratory diseases, such as chronic obstructive pulmonary disease and asthma, affect millions of people all over the world. These diseases are frequently treated with orally inhaled drugs, such as bronchodilators and corticosteroids. Patient response to these drugs is characterized by a great degree of heterogeneity (1). Although efforts have been made to understand this variability at the level of the molecular targets of these drugs (2), another possible source of variability may be found in the absorption pathways across the pulmonary mucosa.

The airways are lined by epithelial cells, which form a physical barrier protecting the lungs from the external environment and express transport proteins belonging to the adenosine triphosphatebinding cassette $(\mathrm{ABC})$ and solute carrier families (3). These transporters recognize several drugs used for the treatment of respiratory diseases as their substrates and may display interindividual variability in their abundance and activity, such as due to disease-associated factors, genetic polymorphisms, or drug-drug interactions. Although transporters have received a great deal of attention as important sources of pharmacokinetic variability of orally and intravenously administered drugs (4), comparatively little information is available on their role at the lung epithelial barrier, where they can regulate the pulmonary disposition of inhaled drugs. This knowledge gap can be potentially filled by nuclear imaging methods, such as PET or SPECT, in combination with radiotracers, which are administered as aerosols into the airways. Although this approach has been used before to assess the pulmonary disposition of some radiolabeled drugs (5-7), very few studies have focused on assessing the activity of pulmonary $\mathrm{ABC}$ or solute carrier transporters as factors potentially contributing to the pharmacokinetic variability of inhaled drugs $(8,9)$.

The most abundant $\mathrm{ABC}$ transporter at the lung epithelial barrier is multidrug resistance-associated protein 1 ( $\mathrm{ABC}$ subfamily $\mathrm{C}$ member 1 [ABCC1]) (10). 6-bromo-7- ${ }^{11} \mathrm{C}$-methylpurine $\left({ }^{11} \mathrm{C}\right.$ $\mathrm{BMP})$ is a PET tracer that has previously been used to assess $\mathrm{ABCC} 1$ activity in the mouse brain (11). ${ }^{11} \mathrm{C}$-BMP is a prodrug radiotracer that crosses cellular membranes by passive diffusion and is then intracellularly converted via glutathione- $S$-transferases into the corresponding glutathione conjugate $S$-(6-(7- ${ }^{11} \mathrm{C}$-methylpurinyl)) glutathione ( $\left.{ }^{11} \mathrm{C}-\mathrm{MPG}\right)$, which is effluxed from cells by $\mathrm{ABCC} 1$ (Fig. 1) (11). One study found pronounced differences between wild-type and $A b c c 1^{(-/-)}$mice in the lung kinetics of radioactivity after intravenous administration of ${ }^{11} \mathrm{C}$-BMP, suggesting that this radiotracer may be suitable to assess pulmonary $\mathrm{ABCC} 1$ activity (12). 


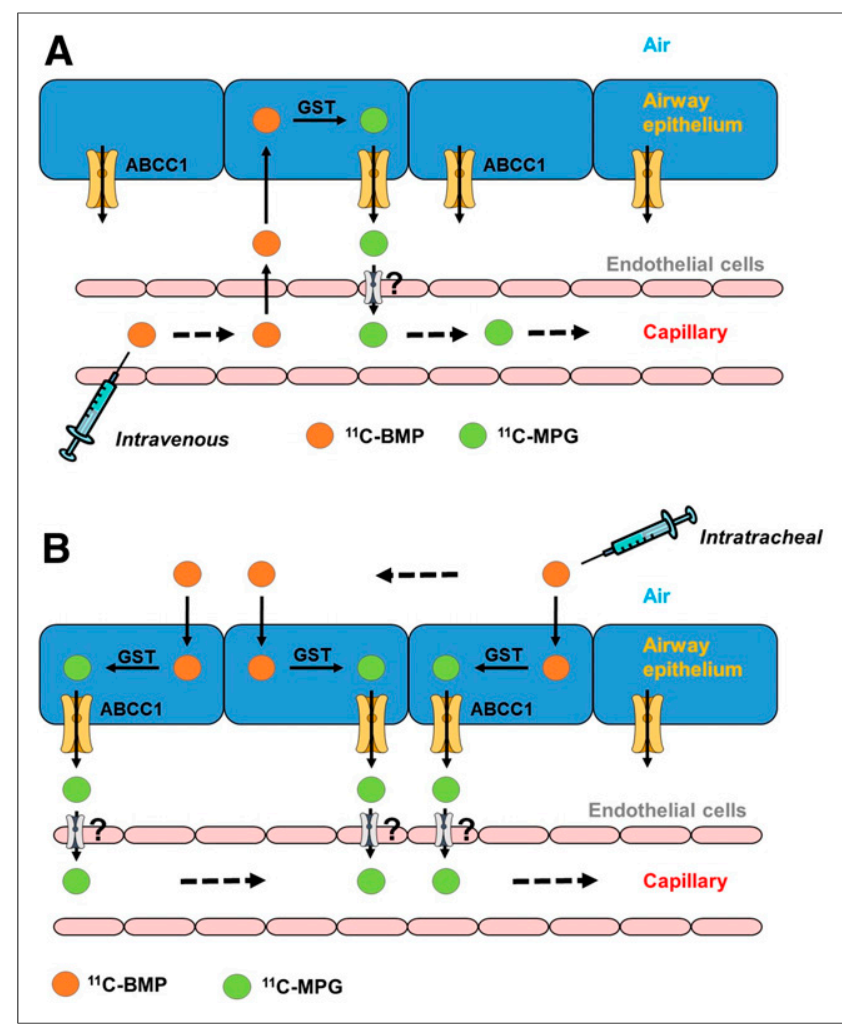

FIGURE 1. Schematic representation of 2 different radiotracer administration modes used in the present work. (A) Prodrug ${ }^{11} \mathrm{C}-\mathrm{BMP}$ is administered intravenously and crosses pulmonary capillary wall and basolateral membrane of pulmonary epithelial cells by passive diffusion. Intracellularly, ${ }^{11} \mathrm{C}$-BMP is converted by glutathione-S-transferases (GST) into corresponding glutathione conjugate ${ }^{11} \mathrm{C}-\mathrm{MPG}$, which is effluxed across basolateral membrane of pulmonary epithelial cells by ABCC1, followed by transfer across capillary endothelial cells by unknown carriers. (B) Prodrug ${ }^{11} \mathrm{C}-\mathrm{BMP}$ is administered intratracheally and crosses luminal membrane of pulmonary epithelial cells by passive diffusion. Intracellularly, ${ }^{11} \mathrm{C}$-BMP is converted by GST into corresponding glutathione conjugate ${ }^{11} \mathrm{C}-\mathrm{MPG}$, which is effluxed across basolateral membrane of pulmonary epithelial cells by ABCC1, followed by transfer across capillary endothelial cells by unknown carriers.

In the present study, we established a protocol to administer ${ }^{11} \mathrm{C}$ BMP into the airways of rats by aerosol to better understand the influence of $\mathrm{ABCC} 1$ on the pulmonary disposition of inhaled $\mathrm{ABCC} 1$ substrate drugs and to investigate whether pulmonary $\mathrm{ABCC} 1$ activity can be assessed with such an imaging protocol. To this end, we directly compared the lung kinetics of ${ }^{11} \mathrm{C}$-BMP-derived radioactivity between wild-type and $A b c c 1^{(-/-)}$rats after both intratracheal and intravenous administration of ${ }^{11} \mathrm{C}-\mathrm{BMP}$ (Fig. 1). To assess the potential translatability of our imaging protocol to humans, we additionally performed in vitro transport experiments on the human distal lung epithelial cell line NCI-H441 (13) with unlabeled BMP.

\section{MATERIALS AND METHODS}

\section{Chemicals}

Unless otherwise stated, all chemicals were purchased from SigmaAldrich or Merck. The ABCC transporter inhibitor MK571 (5-(3-(2-(7chloroquinolin-2-yl)ethenyl)phenyl)-8-dimethylcarbamyl-4,6-dithiaoctanoic acid sodium salt hydrate) was obtained from ApexBio Technology or from Santa Cruz. MK571 was dissolved in phosphate-buffered saline solution at a concentration of $150 \mathrm{mg} / \mathrm{mL}$ and injected intraperitoneally into rats at a volume of $2 \mathrm{~mL} / \mathrm{kg}$ of body weight. Unlabeled BMP and MPG were synthesized as described in the literature (14).

\section{Cell Culture}

NCI-H441 human distal lung epithelial cells (ATCC HTB-174) were purchased from LGC Promochem and cultured according to a previously published protocol (13). Briefly, cells were cultured at $7 \times$ $10^{4}$ cells $/ \mathrm{cm}^{2}$ in 24 -well plates (Greiner Bio-One) using Gibco RPMI 1640 medium (Biosciences), supplemented with 5\% fetal bovine serum and $1 \mathrm{mM}$ sodium pyruvate. The cells were grown in a humidified atmosphere at $37^{\circ} \mathrm{C}$ and $5 \% \mathrm{CO}_{2}$ for $5-8 \mathrm{~d}$, until confluent monolayers were formed.

\section{Radiotracer Synthesis}

${ }^{11} \mathrm{C}$-BMP was synthesized as described before (15) in a decaycorrected radiochemical yield of $4.7 \% \pm 1.1 \%$ (based on ${ }^{11} \mathrm{C}$-methane) with a radiochemical purity of more than $98 \%$ and a molar activity at the end of synthesis of $129 \pm 74 \mathrm{GBq} / \mu \mathrm{mol}(n=24)$. For intravenous or intratracheal administration to rats, ${ }^{11} \mathrm{C}$-BMP was formulated in $0.9 \%$ $(\mathrm{w} / \mathrm{v})$ aqueous saline solution.

\section{Animals}

Female wild-type Sprague-Dawley rats were obtained from JanvierLabs. Female $A b c c 1^{(-)}$rats with a Sprague-Dawley genetic background were obtained from Horizon Discovery (formerly SAGE Labs Inc.). At the time of the experiment, animals weighed $239 \pm 60 \mathrm{~g}$. The animals were housed under controlled environmental conditions $\left(21^{\circ} \mathrm{C} \pm\right.$ $2^{\circ} \mathrm{C}, 40 \%-70 \%$ humidity, 12 -h light/dark cycle) and had free access to a standard laboratory-animal diet (LASQdiet Rod16; LASvendi GmbH) and water. An acclimatization period of at least $1 \mathrm{wk}$ was allowed before the animals were used in the experiments. The study was approved by the national authorities (Amt der Niederösterreichischen Landesregierung), and the study procedures were in accordance with the European Communities Council Directive of September 22, 2010 (2010/63/EU). The animal experimental data reported in this study are in compliance with the ARRIVE (Animal Research: Reporting of in Vivo Experiments) guidelines.

\section{Experimental Design}

An overview of the examined animal groups is given in Table 1. Groups of wild-type and $A b c c 1^{(-)}$rats received a PET scan after intravenous or intratracheal administration of ${ }^{11} \mathrm{C}$-BMP. A further group of wild-type rats received a PET scan after intratracheal administration of ${ }^{11} \mathrm{C}$-BMP at $30 \mathrm{~min}$ after intraperitoneal injection of the ABCC transporter inhibitor MK571 (300 mg/kg). The dose of MK571 was based on previous work (12). In addition, 2 further groups of wild-type rats were used to determine the percentage of unchanged ${ }^{11} \mathrm{C}$-BMP in lung tissue both after intravenous and after intratracheal radiotracer administration.

\section{Intratracheal Aerosol Administration}

Intratracheal aerosol was administered using a Microsprayer (PennCentury, Inc.) connected to a FMJ-250 high-pressure syringe (PennCentury, Inc.) containing $200 \mu \mathrm{L}$ of formulated ${ }^{11} \mathrm{C}$-BMP solution. Under isoflurane anesthesia, the tip of the Microsprayer was introduced into the animals' trachea using a laryngoscope. Aerosol was administered in a laminar flow cabinet to avoid contamination of the operator. Immediately after aerosol administration, PET imaging was performed. The mean time delay between radiotracer administration and the start of the PET data acquisition was $80 \pm 18 \mathrm{~s}$ (range, 64-122 s).

\section{PET Imaging}

Imaging experiments were performed under isoflurane-air anesthesia. Animals were warmed throughout the experiment, and body temperature 
TABLE 1

Overview of Examined Animal Groups and Numbers

\begin{tabular}{|c|c|c|c|c|c|}
\hline \multirow{2}{*}{ Group } & \multirow{2}{*}{ Intravenous } & \multirow{2}{*}{ Intratracheal } & \multirow{2}{*}{ MK571* } & \multicolumn{2}{|c|}{ Metabolism ${ }^{\dagger}$} \\
\hline & & & & Intravenous & Intratracheal \\
\hline \multicolumn{6}{|l|}{ Wild-type } \\
\hline$n$ & 4 & 6 & 3 & 4 & 5 \\
\hline Administered activity (MBq) & $32 \pm 6$ & $30 \pm 12$ & $53 \pm 11$ & $36 \pm 24$ & $45 \pm 20$ \\
\hline Nanomoles ${ }^{\ddagger}$ & $0.7 \pm 0.1$ & $1.7 \pm 0.7$ & $1.7 \pm 0.8$ & $1.6 \pm 0.1$ & $1.6 \pm 0.8$ \\
\hline \multicolumn{6}{|l|}{$A b c c 1^{(-/-)}$} \\
\hline$n$ & 4 & 6 & - & - & - \\
\hline Administered activity (MBq) & $32 \pm 4$ & $29 \pm 4$ & - & - & - \\
\hline Nanomoles ${ }^{\ddagger}$ & $0.6 \pm 0.1$ & $2.2 \pm 0.8$ & - & - & - \\
\hline \multicolumn{6}{|c|}{$\begin{array}{l}{ }^{\star} 300 \mathrm{mg} / \mathrm{kg} \text { injected intraperitoneally at } 30 \text { min before intratracheal application of }{ }^{11} \mathrm{C}-\mathrm{BMP} \text {. } \\
{ }^{\dagger} \text { Five minutes after injection; no PET imaging performed. } \\
{ }^{\ddagger} \text { Administered mass of unlabeled BMP. } \\
\text { Continuous data are shown as mean } \pm \text { SD. }\end{array}$} \\
\hline
\end{tabular}

and respiratory rate were constantly monitored. A microPET Focus220 scanner (Siemens Medical Solutions) was used for PET imaging. ${ }^{11} \mathrm{C}$ BMP was administered either in a volume of $250 \mu \mathrm{L}$ as an intravenous bolus via a tail vein or in a volume of $200 \mu \mathrm{L}$ as an intratracheal aerosol (Table 1 shows the administered radioactivity amount and mass of unlabeled compound). At the start of intravenous administration or shortly after intratracheal administration, a 90-min dynamic PET scan (energy window, 350-750 keV; timing window, $6 \mathrm{~ns}$ ) was initiated. At the end of the PET scan, the animals were euthanized. The lungs were collected for Western blot analysis of the abundance of ABCC1.

\section{Western Blot Analysis}

Rat lung tissue was lysed by suspending a small piece of the organ in $0.5 \mathrm{~mL}$ of ice-cold Invitrogen cell extraction buffer (Thermo Fisher Scientific) containing 1:25 ethylenediaminetetraacetic acid-free cOmplete (Roche) protease inhibitor cocktail followed by a 30-s homogenization step, using an Ultra-Turrax T25 (IKA). The lysate was then sonicated for $10 \mathrm{~s}$ and centrifuged at $17,000 \mathrm{~g}$ for $10 \mathrm{~min}$. The supernatant was transferred to a fresh tube and the pellet discarded. To harvest protein from NCI-H441 cells, a similar protocol without the homogenization step was followed. Tissue and cell samples were kept on ice for all protein extraction steps. The total protein amount in all samples was determined by a Pierce bicinchoninic acid assay (Thermo Fisher Scientific) according to the manufacturer's instructions. Equal amounts of protein $(40 \mu \mathrm{g})$ were mixed with loading buffer and heated to $37^{\circ} \mathrm{C}$ for $30 \mathrm{~min}, 72^{\circ} \mathrm{C}$ for $10 \mathrm{~min}$, or $95^{\circ} \mathrm{C}$ for $5 \mathrm{~min}$. Samples and $10 \mu \mathrm{L}$ of PageRuler Plus (Thermo Fisher Scientific) were loaded onto an $8 \%$ sodium dodecyl sulphate-polyacrylamide gel, and electrophoresis was performed at $100 \mathrm{~V}$. Afterward, a semidry transfer onto immunoblot polyvinylidene fluoride membranes (Bio-Rad) was performed at $22 \mathrm{~V}$ for 40 min using a Trans-Blot SD transfer cell (Bio$\mathrm{Rad})$. Membranes were blocked with $2 \%$ bovine serum albumin (w/v) in washing buffer (phosphate-buffered saline supplemented with $0.05 \%$ polysorbate 20) for $60 \mathrm{~min}$ at room temperature. Membranes were then washed twice and incubated at $4^{\circ} \mathrm{C}$ overnight with a monoclonal rat anti-multidrug resistance-associated protein 1 primary antibody (clone MRPr1, recombinant human multidrug resistance-associated protein 1, 1:50, GTX50894; GeneTex). A monoclonal mouse anti- $\beta$-actin primary antibody (clone AC-15, 1:5,000, A1978; Sigma-Aldrich) was used as the control. The following day, membranes were washed 3 times before incubation for $60 \mathrm{~min}$ at room temperature with a goat-antirat secondary antibody (1:5,000, 50320-200; Alpha Diagnostic) or a goatantimouse secondary antibody (1:5,000, A4416; Sigma-Aldrich). After 3 further washing steps, peroxidase activity was determined using Immobilon western chemiluminescent horseradish peroxidase substrate (Millipore) in a ChemiDoc system (Bio-Rad).

\section{Analysis of Glutathione Conjugation}

In 2 groups of wild-type rats, the percentage of glutathione conjugation of ${ }^{11} \mathrm{C}-\mathrm{BMP}$ in the lungs was analyzed by thin-layer chromatography or high-performance liquid chromatography (HPLC) at 5 min after intravenous $(n=4)$ or intratracheal $(n=5)$ administration of ${ }^{11} \mathrm{C}$-BMP to anesthetized (isoflurane-air) animals. The animals were killed by intracardiac injection of Euthasol (pentobarbital sodium and phenytoin sodium; Vana $\mathrm{GmbH}$ ) under deep anesthesia. The lungs were collected and homogenized using an Ultra Turrax T10 (IKA Laboratory Equipment), and proteins were precipitated with acetonitrile $(1 \mathrm{~mL} / \mathrm{g}$ of lung). The mixture was vortexed and then centrifuged $(12,000 \mathrm{~g}, 1 \mathrm{~min}$, $\left.21^{\circ} \mathrm{C}\right)$. The supernatant $(5 \mu \mathrm{L})$ and diluted radiotracer solution as the reference were spotted on silica gel 60 F254 thin-layer chromatography plates $(10 \times 20 \mathrm{~cm}$; Merck), and the plates were developed in ethyl acetate/ethanol $(9 / 1, \mathrm{v} / \mathrm{v})$. Detection was performed by placing the thin-layer chromatography plates on multisensitive phosphor screens (Perkin-Elmer Life Sciences). The screens were scanned at a 300-dpi resolution using a PerkinElmer Cyclone Plus Phosphor Imager (PerkinElmer Life Sciences). The retardation factor of ${ }^{11} \mathrm{C}$-BMP was 0.35 , whereas the glutathione conjugate ${ }^{11} \mathrm{C}-\mathrm{MPG}$ had an retardation factor of 0.0. In addition, for the group in which ${ }^{11} \mathrm{C}$-BMP was administered intratracheally, the supernatant of the lung extract was analyzed with HPLC using an Agilent 1260 system. Analysis was carried out at $40^{\circ} \mathrm{C}$ using a Macherey-Nagel C18 high-density column (particle size: $5 \mu \mathrm{m}$, length: $250 \mathrm{~mm}$, diameter: $10 \mathrm{~mm}$ ), which was isocratically eluted with acetonitrile/water/aqueous acetic acid (40/60/0.1 v/v/v) at a flow rate of $1 \mathrm{~mL} / \mathrm{min}$. The HPLC eluate was monitored in series for radioactivity and ultraviolet absorption at a wavelength of $254 \mathrm{~nm} .{ }^{11} \mathrm{C}-\mathrm{BMP}$ and ${ }^{11} \mathrm{C}-\mathrm{MPG}$ eluted with retention times of $13.8 \mathrm{~min}$ and $10.5 \mathrm{~min}$, respectively.

\section{Transport Studies}

Uptake studies were performed using NCI-H441 cells cultured in 24-well plates according to a modification of a previously published protocol (16). All experiments were performed in Krebs-Ringer buffer (KRB; $116.4 \mathrm{mM}$ 
$\mathrm{NaCl}, 5.4 \mathrm{mM} \mathrm{KCl}, 0.78 \mathrm{mM} \mathrm{NaH} \mathrm{PO}_{4}, 25 \mathrm{mM} \mathrm{NaHCO} 3,5.55 \mathrm{mM}$ glucose, $15 \mathrm{mM}$ 4-(2-hydroxyethyl)-1-piperazineethanesulfonic acid, $1.8 \mathrm{mM} \mathrm{CaCl}_{2}$, and $0.81 \mathrm{mM} \mathrm{MgSO}_{4} ; \mathrm{pH} \mathrm{7.4)}$ at $37^{\circ} \mathrm{C}$. Cell monolayers were incubated with KRB with or without MK571 $(20 \mu \mathrm{M})$ for $60 \mathrm{~min}$ before experiments were initiated by exchanging the KRB for a solution of unlabeled BMP $(100 \mu \mathrm{M}$ in KRB). Monolayers were incubated for up to $150 \mathrm{~min}$. After 15, 30, 60, 90, 120, and $150 \mathrm{~min}$, respective cells were washed twice with ice-cold KRB and lysed with $1 \%$ (w/v) Triton X-100 (Dow Chemical Co.). The concentration of MPG in all samples was determined by HPLC. For standardization, the total protein amount of cell layers was determined by a Pierce bicinchoninic acid assay according to the manufacturer's instructions.

Efflux studies of MPG were performed under conditions similar to those for the uptake experiments. Cell monolayers were loaded with unlabeled BMP solution $(100 \mu \mathrm{M})$ for $60 \mathrm{~min}$ in the presence or absence of $20 \mu \mathrm{M}$ of MK571. Subsequently, cell monolayers were washed twice with $\mathrm{KRB}$, and either fresh $\mathrm{KRB}$ or KRB containing MK571 $(20 \mu \mathrm{M})$ was added. At 15, 30, 45, 60, 75, 90, 105, and $120 \mathrm{~min}, 200-\mu \mathrm{L}$ samples were taken from the cell supernatant and analyzed by HPLC. Each sample was replaced with an equal volume of the respective transport buffer. Uptake and efflux experiments were performed in triplicate using cells from 3 different passages.

\section{HPLC Analysis}

Samples were analyzed by HPLC according to a modification of a previously published method (11). A Hypersil BDS C18 column (250$4.6 \mathrm{~mm}$; Thermo Fisher Scientific) was isocratically eluted $(0.8 \mathrm{~mL} /$ $\min )$ at $40^{\circ} \mathrm{C}$ with water/acetonitrile $(90 / 10)$ containing $0.1 \%$ trifluoroacetic acid, and ultraviolet detection was performed at $288 \mathrm{~nm}$.

\section{PET Data Analysis}

The dynamic PET data were sorted into 24 frames, which incrementally increased in time length. PET images were reconstructed using Fourier rebinning of the 3-dimensional sinograms followed by 2-dimensional filtered backprojection with a ramp filter, giving a voxel size of $0.4 \times$ $0.4 \times 0.796 \mathrm{~mm}$. Using AMIDE software (17), the left and right lungs were manually outlined on the PET images to derive average (left and right lung) time-activity curves expressed in units of SUV (SUV = [radioactivity per gram of administered radioactivity] $\times$ body weight). The area under the lung time-activity curve from 0 to $80 \mathrm{~min}$ after radiotracer administration $\left(\mathrm{AUC}_{\text {lung }}\right.$ ) was calculated using Prism 8 software (GraphPad Software). From the log-transformed lung timeactivity curves, the elimination slope of radioactivity washout from the lungs $\left(k_{\mathrm{E}, \text { lung }}, \mathrm{h}^{-1}\right)$ was determined by linear regression analysis (12). For the intratracheal group, the linear phase occurred from 0 to $6.25 \mathrm{~min}$ after radiotracer administration for wild-type rats and from 0 to $12.5 \mathrm{~min}$ for $A b c c 1^{(-/-)}$rats; for the intravenous group, the linear phase occurred from 17.5 to $80 \mathrm{~min}$ for both wild-type and Abcc1(-/-) rats.

\section{Statistical Analysis}

With Prism 8 software, differences between 2 groups were analyzed by a 2 -sided $t$ test, and differences between multiple groups were analyzed by 1-way ANOVA followed by a Dunnett multiple-comparison test. The level of statistical significance was set to a $P$ value of less than 0.05 . All values are given as mean $\pm \mathrm{SD}$.

\section{RESULTS}

We used PET to assess the influence of $\mathrm{ABCC} 1$ on the pulmonary kinetics of ${ }^{11} \mathrm{C}$-BMP-derived radioactivity after intravenous or intratracheal administration of ${ }^{11} \mathrm{C}-\mathrm{BMP}$ (Fig. 1). Two different approaches were followed: the use of $A b c c 1^{(-/-)}$rats and the use of pharmacologic inhibition of ABCC1 with MK571. To validate the $A b c c 1$ knockout rat model, we first performed Western blot analysis of $\mathrm{ABCC} 1$ in lung tissue obtained from wild-type and $A b c c 1^{(-/)}$rats, which confirmed absence of ABCC1 in the lungs of $A b c c 1^{(-/-)}$rats (Supplemental Fig. 1; supplemental materials are available at http://jnm.snmjournals.org). In Table 1, an overview of all examined animal groups and corresponding animal numbers is given. In total, 32 animals were used in the experiments. The study procedures were well tolerated by all animals, with no animals dying.

Thin-layer chromatography and HPLC analysis of radioactivity in the lungs at $5 \mathrm{~min}$ after intravenous or intratracheal administration of ${ }^{11} \mathrm{C}$-BMP revealed that more than $98 \%$ of total radioactivity was in the form of the corresponding glutathione conjugate ${ }^{11} \mathrm{C}-\mathrm{MPG}$ (Supplemental Fig. 2).

In Figure 2, serial PET images of wild-type and $A b c c 1^{(-/-)}$rats after intravenous administration of ${ }^{11} \mathrm{C}$-BMP are shown. These images revealed at later time points prolonged retention of radioactivity in the lungs of $A b c \mathrm{Cl}^{(-/-)}$versus wild-type rats. The corresponding time-activity curves are shown in Figure 3A, revealing divergent profiles between the 2 rat strains after an initial distribution phase, that is, at time points more than $10 \mathrm{~min}$ after injection. As quantitative outcome parameters, we determined $\mathrm{AUC}_{\text {lung }}$ and $k_{\mathrm{E} \text {,lung }}$ for the linear elimination phase occurring from 17.5 to $80 \mathrm{~min}$ after radiotracer injection (Supplemental Table 1). $\mathrm{AUC}_{\text {lung }}$ was significantly higher (+77\%, Fig. 3B) and $k_{\mathrm{E} \text {,lung }}$ significantly lower $(-70 \%$, Fig. $3 \mathrm{C})$ in $A b c c l^{(-/-)}$rats than in wild-type rats.

Serial PET images after intratracheal administration of ${ }^{11} \mathrm{C}$ $\mathrm{BMP}$ are shown in Figure 4. In early time frames after the start of the PET acquisition (0-1.5 min), radioactivity was homogeneously distributed in the lungs, supporting the conclusion that intratracheal administration was successful. In 2 of 15 animals, intratracheal administration of ${ }^{11} \mathrm{C}-\mathrm{BMP}$ failed (the esophagus and stomach were visible on the PET images; Supplemental Fig. 3), and these 2 animals (both $A b c c 1^{(-/-)}$) were excluded from analysis. The effect of $A b c c 1$ knockout on the pulmonary kinetics of ${ }^{11} \mathrm{C}$-BMP-derived radioactivity was more pronounced after intratracheal than after intravenous administration and predominantly affected the early part of the pulmonary time-activity curves (from $\sim 0-20 \mathrm{~min}$ after the start of the PET acquisition; Fig. $5 \mathrm{~A})$. Accordingly, $k_{\mathrm{E}, \text { lung }}$ was determined from 0 to $6.25 \mathrm{~min}$ for

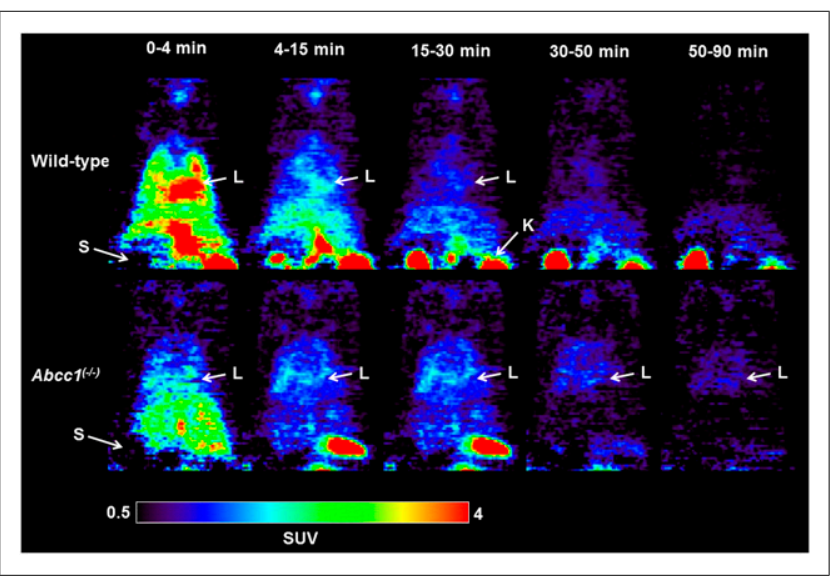

FIGURE 2. Representative coronal PET images at different time points after intravenous administration of ${ }^{11} \mathrm{C}$-BMP into 1 wild-type and 1 Abcc $1^{(-/)}$rat. $\mathrm{L}=$ lung; $\mathrm{S}=$ stomach; $\mathrm{K}=$ kidney. 


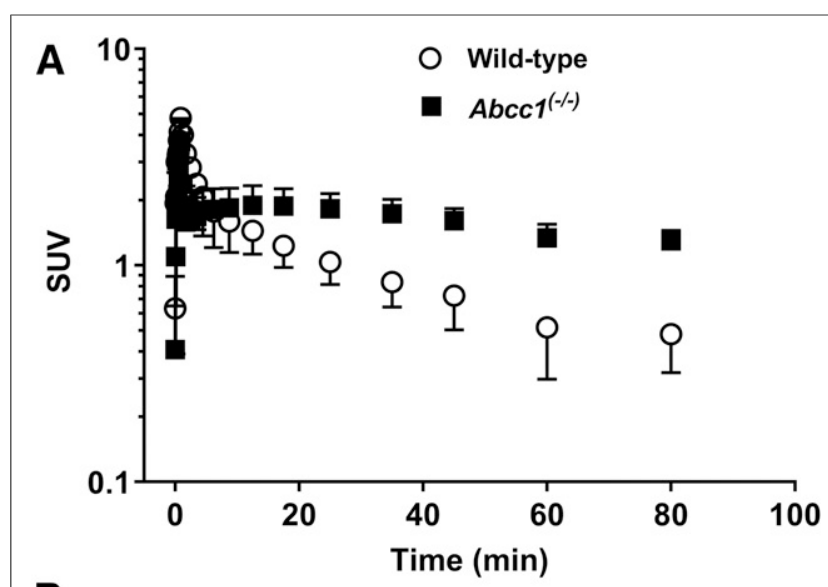

B

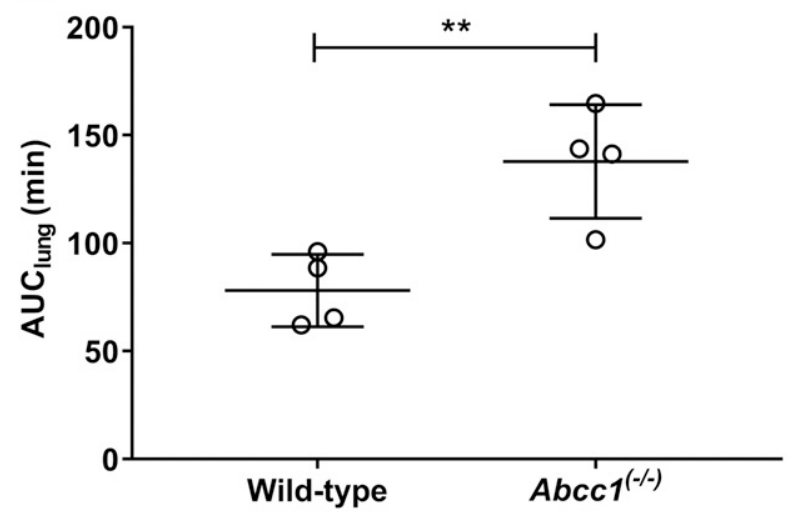

C

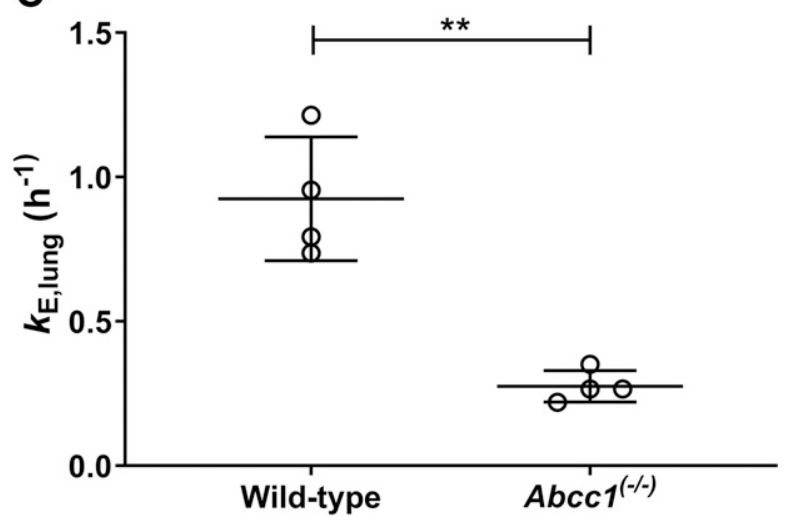

FIGURE 3. Mean $( \pm S D)$ time-activity curves $(A), A C_{\text {lung }}$ values $(B)$, and $k_{\mathrm{E} \text {,lung }}$ values $(\mathrm{C})$ in wild-type rats $(n=4)$ and $A b c c 1^{(-/-)}$rats $(n=$ 4) after intravenous administration of ${ }^{11} \mathrm{C}-\mathrm{BMP}$. ${ }^{\star \star} P<0.01,2$-sided $t$ test.

wild-type rats and from 0 to $12.5 \mathrm{~min}$ for $A b c c 1^{(-/-)}$rats. $k_{\mathrm{E}, \mathrm{lung}}$ values were significantly lower in $A b c c 1^{(-)}$rats than in wildtype rats $( \pm 86 \%$; Fig. $5 \mathrm{C})$, and $\mathrm{AUC}_{\text {lung }}$ values were significantly higher (+352\%; Fig. 5B; Supplemental Table 1). We also assessed the effect of the prototypical ABCC transporter inhibitor MK571 on the pulmonary kinetics of radioactivity after intratracheal administration of ${ }^{11} \mathrm{C}$-BMP (Figs. 4 and 5). Similar to Abccl knockout, pretreatment with MK571 resulted in a significant decrease in $k_{\mathrm{E} \text {,lung }}$ as compared with untreated wild-type rats ( $-20 \%$; Fig. $5 \mathrm{C}$; Supplemental Table 1), although the effect was less pronounced than in $A b c c 1^{(-/-)}$rats. $\mathrm{AUC}_{\text {lung }}$ did not differ between untreated and MK571-pretreated wild-type rats (Fig. 5B).

We performed in vitro transport experiments with unlabeled BMP using monolayers of NCI-H441 cells (Fig. 6). Intracellular accumulation of the glutathione conjugate MPG over time was significantly higher when MK571 was added to the incubation buffer than in the absence of MK571 (Fig. 6A). Moreover, the extracellular efflux of MPG from BMP-loaded NCI-H441 cells was significantly lower in the presence than in the absence of MK571 (Fig. 6B).

\section{DISCUSSION}

The aim of this study was to investigate whether ABCC1 activity at the lung epithelial barrier can be measured with intratracheally administered ${ }^{11} \mathrm{C}$-BMP, a prodrug radiotracer that is rapidly transformed in vivo into a radiolabeled $\mathrm{ABCC} 1$ substrate (12). We found pronounced increases in the pulmonary exposure to ${ }^{11} \mathrm{C}$-BMP-derived radioactivity in $A b c c 1^{(-)-)}$rats as compared with wild-type rats, highlighting the important role ABCC1 may potentially play in controlling the lung disposition of inhaled $\mathrm{ABCC} 1$ substrate drugs. We also demonstrated proof of the concept that there is an ABCC1-mediated drug-drug interaction at the level of the pulmonary epithelium with the prototypical ABCC transporter inhibitor MK571.

$\mathrm{ABCC} 1$ is an $\mathrm{ABC}$ transporter with a wide substrate spectrum that includes several different drugs and has a broadly accepted role in tumor multidrug resistance (18). $\mathrm{ABCC} 1$ is the most abundant $\mathrm{ABC}$ transporter in the human lung, where it is located mainly in the basolateral membrane of bronchial and alveolar epithelial cells $(10,19)$. Quantitative targeted absolute proteomics has revealed a remarkable 18 -fold variability in the abundance of $\mathrm{ABCC} 1$ in the bronchial region among 5 different donors (10). Several inhaled drugs for the treatment of respiratory diseases were found to interact in vitro in lung epithelial cell lines with $\mathrm{ABCC} 1$, including formoterol, budesonide, ipratropium bromide, and $N$-acetyl cysteine (20). Moreover, there is evidence for

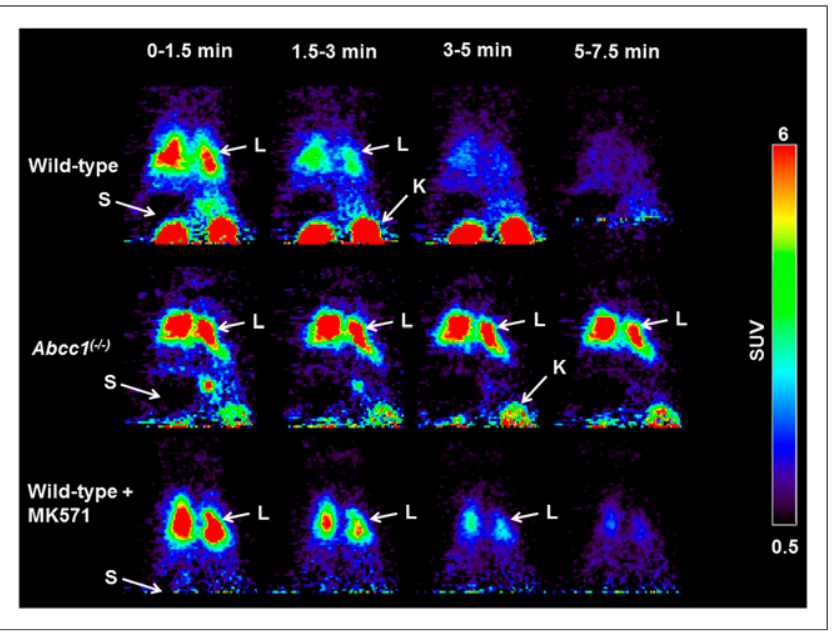

FIGURE 4. Representative coronal PET images at different time points after start of PET acquisition after intratracheal administration of ${ }^{11} \mathrm{C}-\mathrm{BMP}$ into 1 wild-type rat, $1 \mathrm{Abcc1} 1^{(-)}$rat, and 1 wild-type rat pretreated with MK571 at $30 \mathrm{~min}$ before radiotracer administration $(300 \mathrm{mg} / \mathrm{kg}$, intraperitoneally). There was a short delay between intratracheal administration and start of PET acquisition $(80 \pm 18 \mathrm{~s})$. $\mathrm{L}=$ lung; $\mathrm{S}=$ stomach; $\mathrm{K}=$ kidney. 


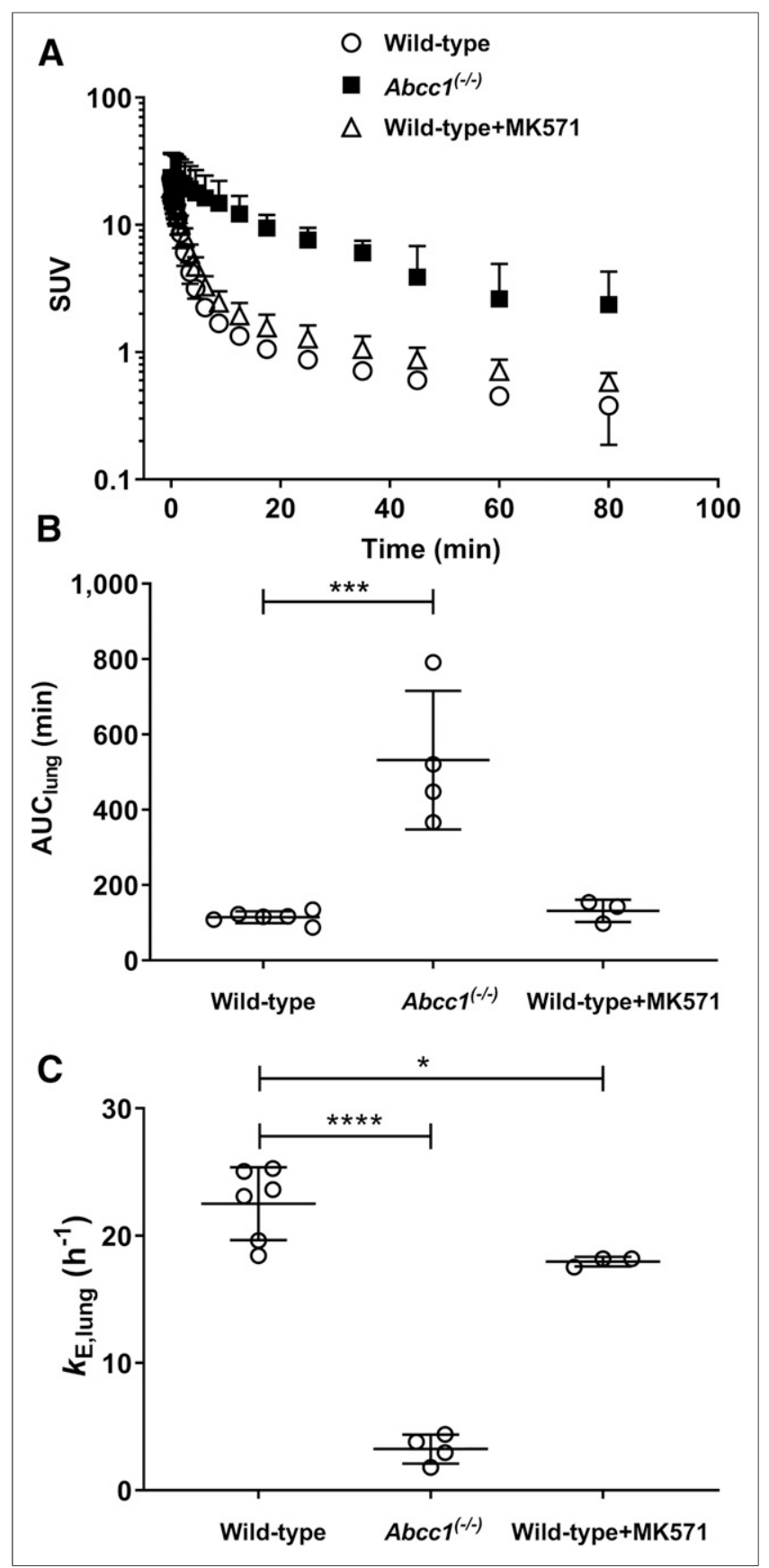

FIGURE 5. Mean $( \pm S D)$ time-activity curves $(A), A \cup C_{\text {lung }}$ values $(B)$, and $k_{\mathrm{E}, \text { lung }}$ values $(\mathrm{C})$ in wild-type rats $(n=6), \operatorname{Abcc1^{(-)}}$ rats $(n=4)$, and MK571-pretreated wild-type rats $(n=3)$ after intratracheal administration of ${ }^{11} \mathrm{C}$-BMP. ${ }^{\star} P<0.05 .{ }^{\star \star \star} P<0.001$. ${ }^{\star \star \star \star} P<0.0001$. $P$ values are for 1-way ANOVA with Dunnett multiple-comparison test.

disease-induced alterations in the abundance of pulmonary ABCC1 (e.g., in chronic obstructive pulmonary disease) (21) as well as for an effect of cigarette smoke extract on pulmonary ABCC1 activity (22). Given its high abundance in the pulmonary epithelium and broad substrate spectrum, $\mathrm{ABCC} 1$ may potentially contribute to interindividual variability in the lung disposition of inhaled drugs and thereby affect therapeutic response.

The applicability of drugs used for the treatment of respiratory diseases as transporter imaging probes for PET or SPECT may be

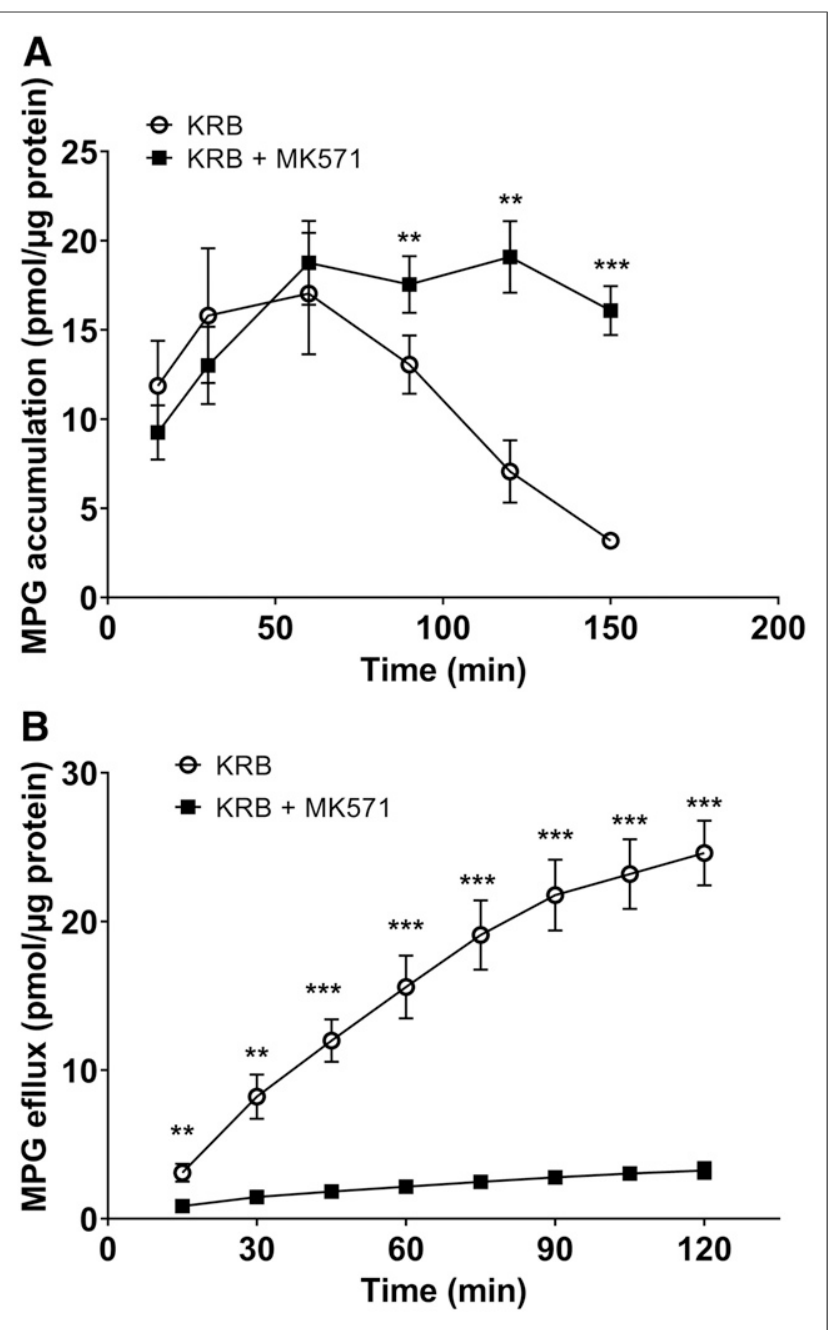

FIGURE 6. (A) Time-dependent accumulation of MPG in NCl-H441 cell monolayers. Cells were incubated with unlabeled BMP $(100 \mu \mathrm{M})$ in KRB without or with MK571 $(20 \mu \mathrm{M})$, and intracellular glutathione conjugate MPG was measured at different time points with HPLC. (B) Time-dependent efflux of MPG from NCl-H441 cell monolayers. Cells were loaded with unlabeled BMP $(100 \mu \mathrm{M})$ in presence or absence of MK571 $(20 \mu \mathrm{M})$. Then, extracellular efflux of MPG in presence or absence of MK571 $(20 \mu \mathrm{M})$ was measured at different time points with HPLC. Data are shown as mean $( \pm S D)$ from 3 independent experiments performed each in triplicate. ${ }^{* *} P<0.01,2$-sided $t$ test. ${ }^{* \star} P<0.001,2$-sided $t$ test.

limited by their lack of selectivity among individual pulmonary ABC transporters. A potentially more powerful approach would therefore be the use of dedicated transporter imaging probes. The SPECT tracer ${ }^{99 \mathrm{~m}} \mathrm{Tc}$-sestamibi is a substrate of P-glycoprotein (ABC subfamily B member 1, ABCB1), and a substrate of ABCC1 has been used to image ABCB1 activity in tumors (23). In a study in which ${ }^{99} \mathrm{~m}$ Tc-sestamibi was administered as an aerosol into the airways of lung cancer and pneumothorax patients, a positive correlation between the pulmonary clearance half-life of ${ }^{99 \mathrm{~m} T c-s e s t a m i b i}$ and the expression of ABCC1 in surgically excised lung tissue was found (9). However, the utility of ${ }^{99 \mathrm{~m}} \mathrm{Tc}$-sestamibi as a radiotracer to image pulmonary $\mathrm{ABCC} 1$ activity is compromised by the fact that ${ }^{99 \mathrm{~m}} \mathrm{Tc}-$ sestamibi is also a substrate of $\mathrm{ABCB} 1$, which works in a transport direction opposite to that of $\mathrm{ABCC} 1$ in the pulmonary epithelium (3).

${ }^{11} \mathrm{C}$-BMP has been developed to visualize $\mathrm{ABCC} 1$ activity in the brain (11). Because ABCC1 preferably transports organic 
anions, ${ }^{11} \mathrm{C}$-BMP has been designed as a prodrug with good passive permeability, which effectively penetrates the blood-brain barrier. Once inside the brain, it is quantitatively converted by intracellular glutathione- $S$-transferases into the hydrophilic glutathione conjugate ${ }^{11} \mathrm{C}-\mathrm{MPG}$, which has poor passive permeability and whose elimination from the brain into the blood is mediated in mice by $\mathrm{ABCC} 1$, organic anion transporter 3 (solute carrier family 22 member $\mathrm{A} 8$ ), and multidrug resistance-associated protein 4 (ABC subfamily C member 4, ABCC4) $(11,24)$. One study found a 17-fold decrease in the elimination rate of radioactivity from the lungs in $A b c c 1^{(-)}$mice relative to wild-type mice after intravenous administration of ${ }^{11} \mathrm{C}$-BMP (12). No differences in pulmonary elimination of radioactivity were found in mice lacking $\mathrm{ABCB} 1$ and breast cancer resistance protein (ABC subfamily $\mathrm{G}$ member 2, ABCG2), suggesting selectivity of this imaging probe for $\mathrm{ABCC} 1$ over $\mathrm{ABCB} 1$ and ABCG2, both of which are also located in the lung epithelium (12).

On the basis of these promising earlier results, we hypothesized that ${ }^{11} \mathrm{C}$-BMP may be suitable to measure the influence of $\mathrm{ABCC} 1$ at the pulmonary epithelium on the lung disposition of inhaled drugs. To this end, we set up a simple and effective protocol for intratracheal administration of aerosolized ${ }^{11} \mathrm{C}$-BMP using the Microsprayer device. We used rats rather than mice, as the larger size of rats facilitated intratracheal radiotracer administration. We could show that ${ }^{11} \mathrm{C}-\mathrm{BMP}$ is, in rat lung tissue, very efficiently converted into its glutathione conjugate within $5 \mathrm{~min}$ after administration (Supplemental Fig. 2), as was consistent with previous mouse data (12).

We used a novel, commercially available Abccl knockout rat model, in which we demonstrated by Western blot analysis absence of $\mathrm{ABCC} 1$ in lung tissue (Supplemental Fig. 1). A direct comparison of intratracheal with intravenous administration of ${ }^{11} \mathrm{C}$-BMP (Fig. 1) revealed that $\mathrm{ABCC} 1$ exerts a greater influence on the pulmonary disposition of radioactivity after intratracheal administration. Knockout of $A b c c l$ led to a marked increase in $\mathrm{AUC}_{\text {lung }}$ and a decrease in $k_{\mathrm{E} \text {,lung }}$ (Fig. 5), as was consistent with a role for $\mathrm{ABCC} 1$ in mediating the efflux of its substrates across the basolateral membrane of epithelial cells into the interstitium (Fig. 1) (3). It can be expected that Abccl knockout led to decreased systemic absorption of ${ }^{11} \mathrm{C}-\mathrm{BMP}-$ derived radioactivity, as was in good agreement with our observation that the kidneys as the main excretory organ were clearly visible on the PET images of wild-type rats but not of $A b c \mathrm{Cl}^{(-/-)}$rats after intratracheal ${ }^{11} \mathrm{C}$-BMP administration (Fig. 4). The pronounced effect of $A b c c 1$ knockout on elimination of radioactivity from the lungs (Fig. 5) suggested lack of functional redundancy between $\mathrm{ABCC} 1$ and other transporters (e.g., ABCC4) in mediating efflux of the radiolabeled glutathione conjugate from pulmonary epithelial cells. However, as ${ }^{11} \mathrm{C}-\mathrm{MPG}$ presumably cannot cross cell membranes by passive diffusion, some active carriers must also be involved in its transfer across endothelial cells of pulmonary capillaries (Fig. 1). Because ABCC1 does not appear to be expressed in the pulmonary endothelium (19), these carriers could be-as at the mouse blood-brain barrier (24) - solute carrier family 22 member $\mathrm{A} 8$ and $\mathrm{ABCC} 4$, both of which have been detected in human lung tissue (10). The influence of $\mathrm{ABCC} 1$ on the pulmonary disposition of clinically used $\mathrm{ABCC} 1$ substrate drugs will most certainly depend on the individual characteristics of each drug (passive permeability, interaction profile with other pulmonary transporters) and may therefore not always be of the same magnitude as for ${ }^{11} \mathrm{C}$-BMP.

We could demonstrate the sensitivity of our imaging protocol to measure a drug-induced modulation of $\mathrm{ABCC} 1$ activity by systemic administration of the non-subtype-selective $\mathrm{ABCC}$ transporter inhibitor MK571. We observed a $20 \%$ reduction of $k_{\mathrm{E} \text {,lung }}$ in MK571-pretreated rats as compared with untreated rats (Fig. 5), suggesting partial inhibition of $\mathrm{ABCC} 1$ in pulmonary epithelial cells and possibly other anion transporters involved in the pulmonary elimination of radioactivity by MK571. Our results indicate that our imaging protocol has the potential to assess $\mathrm{ABCC} 1$-mediated drug-drug interactions in the lung.

Similar to the effects seen in vivo in rats, in vitro transport experiments demonstrated MK571-sensitive flux of unlabeled MPG across monolayers of the human distal lung epithelial cell line NCI-H441 (Fig. 6), which highly expresses ABCC1 (Supplemental Fig. 1). These results support the possibility that MPG is a substrate of human $\mathrm{ABCC} 1$ (14) and that imaging of pulmonary $\mathrm{ABCC} 1$ activity may also be feasible in humans with either intratracheally or intravenously administered ${ }^{11} \mathrm{C}$-BMP. Our imaging protocol may allow a better understanding of the influence of lung disease on the pulmonary disposition of clinically used, inhaled $\mathrm{ABCC} 1$ substrate drugs and potential tailoring of the treatment schedules to the individual pulmonary-barrier properties of each patient.

\section{CONCLUSION}

PET with intratracheally administered ${ }^{11} \mathrm{C}$-BMP can measure $\mathrm{ABCC} 1$ activity at the lung epithelial barrier as a possible determinant of the pulmonary disposition of inhaled $\mathrm{ABCC} 1$ substrate drugs. Our imaging protocol may be potentially applicable in patients to assess the effects of disease, genetic polymorphisms, or drug-drug interactions on pulmonary $\mathrm{ABCC} 1$ activity. The imaging-based assessment of the barrier properties of the pulmonary epithelium may open an entirely new field of research, which may contribute to a better understanding of the sources of variability in treatment response to inhaled therapeutics and ultimately provide patients with more effective drugs.

\section{DISCLOSURE}

Financial support was provided by the Lower Austria Corporation for Research and Education (NÖ Forschungs-und Bildungsges.mbH [NFB]) (LS17-009, to Oliver Langer). No other potential conflict of interest relevant to this article was reported.

\section{ACKNOWLEDGMENTS}

We thank Mathilde Löbsch for help in conducting the PET experiments and Dr. Ben Forbes (King's College London, U.K.) for providing the Microsprayer.

\section{KEY POINTS}

QUESTION: Can ABCC1 at the lung epithelial barrier affect the pulmonary disposition of inhaled $A B C C 1$ substrates and thereby potentially contribute to variability in the therapeutic response to drugs used for the treatment of chronic respiratory diseases?

PERTINENT FINDINGS: We found that knockout of $A b c c 1$ led to severalfold increases in lung radioactivity exposure after intratracheal administration of ${ }^{11} \mathrm{C}$-BMP. The effect of $\mathrm{ABCC} 1$ on the pulmonary disposition of radioactivity was more pronounced after intratracheal than after intravenous radiotracer administration.

IMPLICATIONS FOR PATIENT CARE: PET with intratracheally administered ${ }^{11} \mathrm{C}$-BMP may be applied in patients to assess interindividual differences in lung epithelial barrier properties and thereby potentially tailor treatment schedules to the individual characteristics of each patient. 


\section{REFERENCES}

1. Drazen JM, Silverman EK, Lee TH. Heterogeneity of therapeutic responses in asthma. Br Med Bull. 2000;56:1054-1070.

2. García-Menaya JM, Cordobes-Duran C, Garcia-Martin E, Agundez JAG. Pharmacogenetic factors affecting asthma treatment response. potential implications for drug therapy. Front Pharmacol. 2019;10:520.

3. Nickel S, Clerkin CG, Selo MA, Ehrhardt C. Transport mechanisms at the pulmonary mucosa: implications for drug delivery. Expert Opin Drug Deliv. 2016;13:667-690.

4. Giacomini KM, Huang SM, Tweedie DJ, et al. Membrane transporters in drug development. Nat Rev Drug Discov. 2010;9:215-236.

5. van Waarde A, Maas B, Doze P, et al. Positron emission tomography studies of human airways using an inhaled beta-adrenoceptor antagonist, S- ${ }^{11} \mathrm{C}-\mathrm{CGP}$ 12388. Chest. 2005; 128:3020-3027.

6. Borgström L, Newman S, Weisz A, Moren F. Pulmonary deposition of inhaled terbutaline: comparison of scanning gamma camera and urinary excretion methods. J Pharm Sci. 1992;81:753-755.

7. Berridge MS, Lee Z, Heald DL. Pulmonary distribution and kinetics of inhaled $\left[{ }^{11} \mathrm{C}\right]$ triamcinolone acetonide. J Nucl Med. 2000;41:1603-1611.

8. Ruparelia P, Cheow HK, Evans JW, et al. Pulmonary elimination rate of inhaled ${ }^{99 \mathrm{~m}} \mathrm{Tc}$-sestamibi radioaerosol is delayed in healthy cigarette smokers. $\mathrm{Br} \mathrm{J} \mathrm{Clin}$ Pharmacol. 2008;65:611-614.

9. Mohan HK, Routledge T, Cane P, Livieratos L, Ballinger JR, Peters AM. Does the clearance of inhaled ${ }^{99 \mathrm{~m}} \mathrm{Tc}$-sestamibi correlate with multidrug resistance protein 1 expression in the human lung? Radiology. 2016;280:924-930.

10. Sakamoto A, Matsumaru T, Yamamura N, et al. Quantitative expression of human drug transporter proteins in lung tissues: analysis of regional, gender, and interindividual differences by liquid chromatography-tandem mass spectrometry. J Pharm Sci. 2013;102:3395-3406.

11. Okamura T, Kikuchi T, Okada M, et al. Noninvasive and quantitative assessment of the function of multidrug resistance-associated protein 1 in the living brain. $J$ Cereb Blood Flow Metab. 2009;29:504-511.

12. Okamura T, Kikuchi T, Okada M, Wakizaka H, Zhang MR. Imaging of activity of multidrug resistance-associated protein 1 in the lungs. Am J Respir Cell Mol Biol. 2013;49:335-340.
13. Salomon JJ, Muchitsch VE, Gausterer JC, et al. The cell line NCl-H441 is a useful in vitro model for transport studies of human distal lung epithelial barrier. Mol Pharm. 2014;11:995-1006.

14. Okamura T, Kikuchi T, Fukushi K, Arano Y, Irie T. A novel noninvasive method for assessing glutathione-conjugate efflux systems in the brain. Bioorg Med Chem. 2007; 15:3127-3133.

15. Zoufal V, Mairinger S, Krohn M, et al. Influence of multidrug resistance-associated proteins on the excretion of the $\mathrm{ABCC1}$ imaging probe 6-bromo-7-[ $\left[{ }^{11} \mathrm{C}\right]$ methylpurine in mice. Mol Imaging Biol. 2019;21:306-316.

16. Nickel S, Selo MA, Fallack J, et al. Expression and activity of breast cancer resistance protein (BCRP/ABCG2) in human distal lung epithelial cells in vitro. Pharm Res. 2017;34:2477-2487.

17. Loening AM, Gambhir SS. AMIDE: a free software tool for multimodality medical image analysis. Mol Imaging. 2003;2:131-137.

18. Cole SP. Multidrug resistance protein 1 (MRP1, ABCC1), a "multitasking" ATP-binding cassette (ABC) transporter. J Biol Chem. 2014;289:3088030888.

19. Scheffer GL, Pijnenborg AC, Smit EF, et al. Multidrug resistance related molecules in human and murine lung. J Clin Pathol. 2002;55:332-339.

20. van der Deen M, Homan S, Timmer-Bosscha H, et al. Effect of COPD treatments on MRP1-mediated transport in bronchial epithelial cells. Int J Chron Obstruct Pulmon Dis. 2008;3:469-475.

21. van der Deen M, Marks H, Willemse BW, et al. Diminished expression of multidrug resistance-associated protein 1 (MRP1) in bronchial epithelium of COPD patients. Virchows Arch. 2006;449:682-688.

22. van der Deen M, de Vries EG, Visserman H, et al. Cigarette smoke extract affects functional activity of MRP1 in bronchial epithelial cells. J Biochem Mol Toxicol. 2007;21:243-251.

23. Taki J, Sumiya H, Asada N, Ueda Y, Tsuchiya H, Tonami N. Assessment of Pglycoprotein in patients with malignant bone and soft-tissue tumors using technetium99m-MIBI scintigraphy. J Nucl Med. 1998;39:1179-1184.

24. Okamura T, Okada M, Kikuchi T, Wakizaka H, Zhang MR. Mechanisms of glutathione-conjugate efflux from the brain into blood: Involvement of multiple transporters in the course. J Cereb Blood Flow Metab. 2020;40:116125 . 